RESEARCH REPORT

\title{
Contribution of drinking patterns to differences in rates of alcohol related problems between three urban populations
}

\author{
M Bobak, R Room, H Pikhart, R Kubinova, S Malyutina, A Pajak, S Kurilovitch, R Topor, Y Nikitin, \\ $M$ Marmot
}

J Epidemiol Community Health 2004;58:238-242. doi: 10.1136/jech.2003.011825

See end of article for authors' affiliations

Correspondence to: Dr M Bobak, International Centre for Health and Society, Department of Epidemiology and Public Health, University College London, 1-19 Torrington Place, London WCIE 6BT, UK; martinb@ public-health.ucl.ac.uk

Accepted for publication 1 September 2003
Objectives: To examine, on empirical data, whether drinking patterns, in addition to overall alcohol consumption, contribute to differences in rates of alcohol related problems between populations.

Design: Cross sectional survey.

Settings: One Russian, one Polish, and one Czech city.

Participants: 1118 men and 1125 women randomly selected from population registers.

Main outcome measures: Problem drinking; negative social consequences of drinking; alcohol consumption and drinking pattern.

Results: Rates of problem drinking and of negative consequences of drinking were much higher in Russian men (35\% and $18 \%$, respectively) than in Czechs (19\% and $10 \%$ ) or Poles (14\% and $8 \%$ ). This contrasts with substantially lower mean annual intake of alcohol reported by Russian men ( 4.6 litres) than by Czech men (8.5 litres), and with low mean drinking frequency in Russia ( 67 drinking sessions per year, compared with 179 sessions among Czech men). However, Russians consumed the highest dose of alcohol per drinking session (means $71 \mathrm{~g}$ in Russians, $46 \mathrm{~g}$ in Czechs, and $45 \mathrm{~g}$ in Poles), and had the highest prevalence of binge drinking. In women, the levels of alcohol related problems and of drinking were low in all countries. In ecological and individual level analyses, indicators of binge drinking explained a substantial part of differences in rates of problem drinking and negative consequences of drinking between the three countries.

Conclusions: These empirical data confirm high levels of alcohol related problems in Russia despite low volume of drinking. The binge drinking pattern partly explains this paradoxical finding. Overall alcohol consumption does not suffice as an estimate of alcohol related problems at the population level.
$\mathrm{T}$ here is a large body of evidence that the mean alcohol consumption is a powerful determinant of alcohol related problems, both at the individual and population level. ${ }^{1}$ It has been recognised, however, that mean consumption is an incomplete predictor of risk, and attention is increasingly turning to drinking patterns. ${ }^{2}$ An often used example is of one person drinking two drinks every evening and another drinking only on Friday and Saturday nights, but consuming seven drinks on each of these evenings. Both are drinking 14 drinks per week, but the difference in patterns makes a difference in their risk for social and casualty consequences ${ }^{3}$ and, as it is increasingly clear, also for some long term health consequences. ${ }^{4}$

Drinking pattern is important for a person but there is emerging evidence that this is true at the population level as well. Time series analyses of western European data suggest that a given change in the level of drinking has more effect in the Nordic countries than in southern Europe. ${ }^{67}$ Drinking patterns have been proposed as part of the explanation of the differential effects of per capita alcohol consumption on mortality from alcohol related causes.?

Recently, working from a combination of survey data and expert judgements, Gmel et $a l^{8}$ and Rehm et al have developed a hazardous patterns score, ranging from 1 (lowest risk) to 4 (highest risk), which combines scores in six dimensions: high quantities of drinking per occasion; frequency of getting drunk; festive drinking being common; drinking in public places being common; drinking with meals being uncommon; low rate of daily drinking. In principle, the score is measuring not the overall rate of hazardous drinking, but the degree of hazard associated with each extra per capita litre of alcohol consumed. In the most recent version of the scoring, the Czech Republic is scored at 2 (the same as for Germany), Poland at 3 (the same as for Sweden), and Russia at $4 .^{10}$

The objective of this paper is to examine, on empirical individual level data, whether drinking patterns, in addition to overall alcohol consumption, contribute to differences in rates of alcohol related problems between populations. We used data on alcohol consumption and drinking patterns in Russia, Poland, and the Czech Republic. These countries present an interesting example: alcohol related problems are high in Russia," although the officially recorded alcohol consumption in Russia (8.1 litres of pure alcohol per person aged 15+ in 1996) is similar to that in Poland (7.9 litres) and lower than in the Czech Republic (14.4 litres). ${ }^{12}$ (According to some estimates the consumption in Russia may be substantially higher when unrecorded consumption is added in). ${ }^{11}$ According to the country scoring described above, ${ }^{89}$ the problems per unit of alcohol should be highest in Russia and lowest in the Czech Republic, and differences between the countries in the rates of drinking should be at least partly explained by taking drinking patterns into account.

\section{METHODS}

\section{Study populations}

The HAPIEE (health, alcohol and psychosocial factors in Eastern Europe) study was a cross sectional study in urban population samples in Novosibirsk (Russia), Krakow (Poland), and the twin city Karvina-Havirov (Czech Republic). The study was conducted in 1999-2000. Men and women aged 45-64 were randomly selected from 
population registers. In Poland and the Czech Republic, data were collected during home interviews (after sending an explanatory letter inviting the subjects to participate in the study), and in a short examination in a clinic. In Russia, home visits to the first 50 participants yielded very low response rates (because of respondents' fears of crime) and participants were therefore interviewed in a clinic. Response rates were $70 \%$ in Russia, $65 \%$ in Poland, and $71 \%$ in the Czech Republic.

\section{Measures of drinking}

Participants completed a structured questionnaire, which was then checked by an interviewer. The questionnaire collected extensive data on participants' medical history, socioceonomic status, psychosocial factors, and diet. Three measures of alcohol consumption were available. Firstly, respondents were asked about their drinking patterns using the graduated frequency (GF) method: how often during the past 12 months did the subjects drink more than $\mathrm{X}$ amount of alcohol. ${ }^{13}$ In the version of the GF used in this study, there were nine mutually exclusive categories of frequency, ranging from "never" to "every day", and seven mutually exclusive categories of alcohol dose (expressed in local units of beer, wine, and spirits), ranging from $10 \mathrm{~g}$ to $\geqslant 160$ of pure alcohol (details available from authors). Secondly, respondents were asked the largest amount of beer, wine, and spirits consumed on one occasion during each of the past year, the past month, and the past week. And thirdly, they were asked their frequency of alcohol intoxication and of amnesia (being unable to remember what had happened the morning after drinking) during the past year.

From the graduated frequency responses, measures were derived of the frequency of drinking in the past year, the number of drinking occasions in the past year, the average dose per occasion, the annual alcohol intake, and the frequency of binge drinking during the past year. Alcohol intake measures were recalculated into grams of ethanol. We used several definitions of binge drinking: $\geqslant 80, \geqslant 120$, and $\geqslant 160 \mathrm{~g}$ of ethanol at least once a month and at least once a week. In Russia, in addition, serum $\gamma$-glutamyltransferase (GGT) was measured in a subsample of subjects; the alcohol measures correlated strongly with serum GGT. ${ }^{14}$

\section{Alcohol related problems}

There were two measures of alcohol related problems. The participants completed the CAGE questionnaire, ${ }^{15}$ asked concerning the preceding 12 months (Cronbach's $\alpha$ 0.75), and a questionnaire on life area problems from drinking, adapted from items that have been used in north America ${ }^{3} 16$ and western Europe. ${ }^{17}$ (Cronbach's $\propto$ 0.69). For both

\section{Key points}

- The overall volume of drinking predicts alcohol related problems in populations but it is an incomplete predictor. Drinking patterns have been shown to predict alcohol problems in individuals but there is little empirical evidence whether drinking patterns contribute to differences in alcohol related problems between populations.

- In empirical data from three populations, we found that differences in rates of alcohol problems were related to indicators of binge drinking. Drinking patterns thus contribute to rates of alcohol related problems at population level. questionnaires, two or more positive answers were taken as problematic.

\section{Statistical analyses}

Percentages and means were calculated. The population samples had virtually identical age structure, and we therefore present the unadjusted estimates. Statistical significance of the differences between populations was assessed by a $\chi^{2}$ test for categorical variables and by one way analysis of variance for continous variables, separately for men and women. Logistic and linear regressions were used to predict differences in alcohol related problems by drinking characteristics; clustering of subjects within populations was taken into account by the "cluster" option in Stata (Stata Corporation, College Station, USA). Results using the CAGE and problem drinking scales as continuous variables were similar to those using dichotomised outcome variables.

\section{RESULTS}

Sociodemographic characteristics (not shown in tables) were consistent with official information about the study centres. The mean age ranged from $\mathbf{5 4 . 5}$ years in Polish women to 55.6 years in Russian men. Table 1 shows drinking levels in the three populations by sex. Among both men and women, abstention (not drinking at all in the past year) was most common in the Polish sample, and least common in the Czech sample, and drinking frequency was highest in Czechs and lowest in Russians. The reported average annual volume of drinking, based on the graduated frequency questionnaire, in the Czech Republic was about double the levels in Russia and Poland (table 1). By contrast, among men, all indices of binge drinking were highest for the Russian sample, while the rates among Polish men were a little lower than among Czech men. The mean alcohol dose per drinking session was also highest in Russian men, with the mean dose about the same for Polish and Czech men. One measure of heavy drinking, however, pointed in the opposite direction. When asked the largest amount they had consumed in the past year, it was Czech men who gave the highest answer, and Russian men the lowest. On a shorter time frame, howeverthe past week-the mean response from men was similar in the three samples. Among women, binge drinking was uncommon but there were significant differences in most drinking indices between the populations.

Negative consequences of drinking, for all kinds of life area problems, were most common in Russian men (table 2). More than a third of Russian men scored at least two points on the CAGE questionnaire. Among women, too, Russians were most likely to report negative consequences of drinking, but Czech women had the highest prevalence of problem drinking (CAGE). However, in women the absolute numbers of negative consequences were small and estimates were unstable.

As an ecological test of the relation of the occurrence of drinking problems to drinking patterns, rather than simply to volume of drinking, three ratios were computed for each centre (table 3 ) from the aggregate population data shown in tables 1 and 2. Russian men and women showed a considerably higher index of problems per litre (ratio of the prevalence of 2 or more problems to average annual intake) than their Polish and Czech counterparts. The ratio was about equal for Czech men and women, but higher for women among Russians and for men among Poles. The ratio of the problem rate to the mean dose per session (a measure of general clustering of drinking into heavier occasions) showed a much more even result, particularly among men. A third ratio, of the problem rate to the rate of drinking at least $120 \mathrm{~g}$ of ethanol on an occasion (about 10 drinks) at least once a month, evened out the result entirely between the men in the 
Table 1 Alcohol consumption indices, by country and sex

\begin{tabular}{|c|c|c|c|c|c|c|c|c|}
\hline & \multicolumn{4}{|l|}{ Men } & \multicolumn{4}{|l|}{ Women } \\
\hline & \multirow{2}{*}{$\frac{\text { Russia }}{n=515}$} & \multirow{2}{*}{$\begin{array}{l}\text { Poland } \\
n=284\end{array}$} & \multirow{2}{*}{$\frac{\text { Czech R }}{n=319}$} & \multirow[b]{2}{*}{ p Value* } & \multirow{2}{*}{$\frac{\text { Russia }}{n=475}$} & \multirow{2}{*}{$\begin{array}{l}\text { Poland } \\
n=292\end{array}$} & \multirow{2}{*}{$\frac{\text { Czech R }}{n=358}$} & \multirow[b]{2}{*}{ p Value* } \\
\hline & & & & & & & & \\
\hline \multicolumn{9}{|l|}{ Frequency of drinking (from GF) } \\
\hline$\geqslant 5$ times/week & 5 & 15 & 35 & $<0.001$ & 0.6 & 12 & 8 & $<0.001$ \\
\hline 1-4 times/week & 31 & 21 & 36 & & 5 & 7 & 20 & \\
\hline 1-3 times/month & 35 & 24 & 11 & & 26 & 18 & 22 & \\
\hline 3-11 times/year & 14 & 21 & 6 & & 43 & 26 & 15 & \\
\hline $1-2$ times/year & 4 & 6 & 6 & & 10 & 14 & 19 & \\
\hline Never in the past year & 11 & 14 & 6 & & 16 & 24 & 17 & \\
\hline \multicolumn{9}{|l|}{ Binge drinking (from GF) } \\
\hline$\geqslant 80 \mathrm{~g}$ at least once a month & 30 & 12 & 17 & $<0.001$ & 1 & 2 & 4 & 0.02 \\
\hline$\geqslant 120 \mathrm{~g}$ at least once a month & 16 & 7 & 9 & 0.001 & 0.6 & 1 & 2 & 0.12 \\
\hline$\geqslant 160 \mathrm{~g}$ at least once a month & 12 & 4 & 6 & $<0.001$ & 0.6 & 0.7 & 1.7 & 0.28 \\
\hline$\geqslant 80 \mathrm{~g}$ at least once a week & 10 & 4 & 6 & 0.002 & 0.7 & 0.4 & 0.3 & 0.72 \\
\hline$\geqslant 120 \mathrm{~g}$ at least once a week & 5 & 2 & 3 & 0.040 & 0.4 & 0.3 & 0 & 0.48 \\
\hline$\geqslant 160 \mathrm{~g}$ at least once a week & 4 & 1 & 2 & 0.002 & 0.4 & 0 & 0 & 0.26 \\
\hline Mean average dose per drinking session (g of ethanol) $\dagger$ & 70.8 & 45.8 & 44.8 & $<0.001$ & 26.9 & 22.9 & 30.7 & $<0.001$ \\
\hline Mean number of drinking sessions per year & 66.5 & 78.7 & 179.3 & $<0.001$ & 14.7 & 22.9 & 43.3 & $<0.001$ \\
\hline Mean annual intake (litres of ethanol) & 4.64 & 4.08 & 8.50 & $<0.001$ & 0.60 & 0.72 & 1.42 & 0.005 \\
\hline \multicolumn{9}{|l|}{ Largest amount consumed at one session (g of ethanol)‡ } \\
\hline In the past year & 125.9 & 144.7 & 160.9 & 0.07 & 32.7 & 76.4 & 74.7 & $<0.001$ \\
\hline In the past month & 89.1 & 103.5 & 101.9 & 0.19 & 24.0 & 42.6 & 48.8 & $<0.001$ \\
\hline In the past week & 67.1 & 72.2 & 70.4 & 0.59 & 21.7 & 37.8 & 33.6 & $<0.001$ \\
\hline
\end{tabular}

*Statistical significance for differences between populations; †drinkers only; famong those who reported any alcohol in the past year, month, and week, respectively.

three countries. Results for women were unstable, mainly because of low underlying rates, but among men the average social and health "trouble per binge drinker" seems to be similar in the three societies.

Table 4 shows analyses that examined whether differences in the rates of alcohol related outcomes in men between the three countries could be explained by using individual level drinking characteristics. This was done by assessing the changes in odds ratios after including the mean dose per session into (a) a crude model, (b) model adjusted for the annual intake, and (c) model adjusted for the annual intake and drinking frequency. The crude odds ratio of problem drinking in Russian men, compared with Czechs, was 2.4; adjustment for mean dose per session reduced it to 1.6. The odds ratio adjusted for annual volume was 3.6, consistent with the hypothesis that for a fixed volume of alcohol consumption Russian drinking patterns are more harmful than drinking patterns in the Czech Republic or in Poland; further controlling for mean dose reduced the odds ratio to 2.4 , a reduction of $46 \%$. Similarly, the odds ratio adjusted for both annual consumption and drinking frequency was 4.4, and further adjustment for the mean dose per drinking session reduced the odds ratio to 2.7 (a reduction of 50\%). Results for negative consequences of drinking in men and for both outcomes in women (not shown) were similar.

\section{DISCUSSION}

These empirical data from three countries of central and eastern Europe show that, in men, the prevalence of alcohol related problems was highest in Russia, despite a relatively low reported per capita alcohol intake, while it was relatively low in the Czech Republic, with a much higher per capita intake. Women in all three countries drank little, and there were no clear differences in the rates of alcohol related problems in women. The results in men are consistent with

Table 2 Frequency (\%) of alcohol problem measures, by country and sex

\begin{tabular}{|c|c|c|c|c|c|c|c|c|}
\hline & \multicolumn{4}{|l|}{ Men } & \multicolumn{4}{|l|}{ Women } \\
\hline & \multirow{2}{*}{$\frac{\text { Russia }}{n=515}$} & \multirow{2}{*}{$\begin{array}{l}\text { Poland } \\
n=284\end{array}$} & \multirow{2}{*}{$\frac{\text { Czech R }}{n=319}$} & \multirow[b]{2}{*}{ p Value* } & \multirow{2}{*}{$\frac{\text { Russia }}{n=475}$} & \multirow{2}{*}{$\frac{\text { Poland }}{n=292}$} & \multirow{2}{*}{$\begin{array}{l}\text { Czech R } \\
n=358\end{array}$} & \multirow[b]{2}{*}{ p Value* } \\
\hline & & & & & & & & \\
\hline \multicolumn{9}{|l|}{ In the past 12 months, drinking caused difficulties with: } \\
\hline marriage/partner or home life & 20.9 & 7.6 & 9.9 & $<0.001$ & 3.5 & 0 & 1.2 & 0.004 \\
\hline friendships and social life & 4.2 & 1.9 & 2.2 & 0.25 & 1.5 & 0 & 0.3 & 0.09 \\
\hline work & 7.7 & 0.4 & 0.6 & $<0.001$ & 0.3 & 0.4 & 0.6 & 0.64 \\
\hline police or other authorities & 3.3 & 0.4 & NA & 0.02 & 0.3 & 0 & NA & 0.50 \\
\hline physical health & 18.3 & 11.7 & 16.2 & 0.19 & 8.5 & 3.0 & 3.5 & 0.01 \\
\hline psychological or mental health & 6.2 & 4.9 & 4.5 & 0.65 & 1.8 & 0.4 & 1.8 & 0.34 \\
\hline financial circumstances & 16.5 & 6.4 & 6.1 & $<0.001$ & 2.0 & 0.8 & 2.1 & 0.63 \\
\hline Difficulties score $\geqslant 2$ & 17.9 & 8.2 & 10.3 & $<0.001$ & 2.9 & 0.7 & 1.8 & 0.12 \\
\hline \multicolumn{9}{|l|}{ CAGE score } \\
\hline 0 & 49.9 & 72.4 & 65.6 & & 90.7 & 96.8 & 91.8 & \\
\hline 1 & 15.3 & 14.0 & 15.9 & & 6.6 & 2.5 & 4.7 & \\
\hline 2 & 15.3 & 5.9 & 8.3 & $<0.001$ & 2.4 & 0.7 & 3.2 & 0.06 \\
\hline 3 & 13.3 & 5.1 & 7.3 & & 0.2 & 0 & 0.3 & \\
\hline 4 & 6.1 & 2.6 & 2.9 & & 0 & 0 & 0 & \\
\hline CAGE score $\geqslant 2$ & 34.8 & 13.7 & 18.5 & $<0.001$ & 2.6 & 0.7 & 3.5 & 0.07 \\
\hline
\end{tabular}


Table 3 Ratios of alcohol problems to drinking pattern indices by country and sex

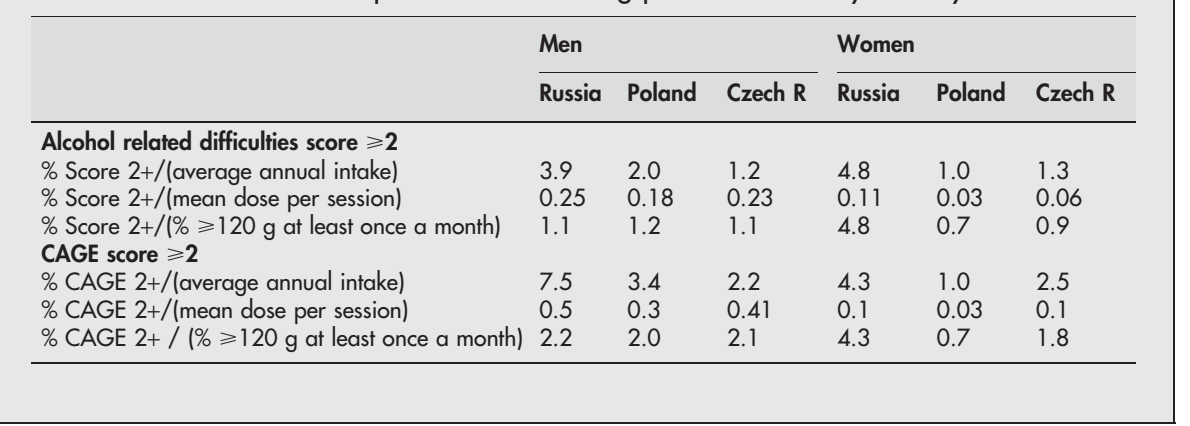

the hypothesis that a given volume of drinking is more harmful in Russia than in the other two countries.

It is unlikely that the results are attributable to methodological problems, such as absence of nationally representative samples, non-responses, and reliance on self report in measurement of alcohol intake. While it is possible that the selected urban centres are not entirely representative for the whole countries, the differences between the three populations probably reflect differences between countries. Nemtsov's data suggest that Novosibirsk is fairly typical for Russia in terms of alcohol intake. ${ }^{11}$ Compared with the national average, the overall levels of alcohol consumption in Krakow may be somewhat underestimated and in Karvina somewhat overestimated but overall the drinking patterns in Novosibirsk, Krakow, and Karvina/Havirov probably approximate those for Russia, Poland, and the Czech Republic, respectively.

Non-response bias should not have affected the comparisons between populations. Subjects in all three cities were selected randomly from population registers, and response rates were similar in all centres. It is probable that nonresponders include heavy drinkers but, assuming similar reasons for non-response in all centres, this would affect all samples to a similar extent.

Alcohol intake was self reported, but in Russia it was strongly associated with serum GGT (this was not measured in Czech Republic and Poland). The graduated frequency technique has been suggested as a reliable method to assess drinking pattern. ${ }^{18}$ We used local units of alcohol consumption, and the technique was acceptable to the study subjects. In each of the three samples, reported annual consumption was about one third of the national recorded per capita consumption. Substantial underreporting of total volume of consumption is usual in alcohol surveys, ${ }^{19}$ and has been found also in previous surveys in Russia. ${ }^{20}$ Anecdotal evidence suggests that social stigma associated with alcohol is small in Russia ${ }^{21}$; the relatively low annual intake in Russia is therefore unlikely to be a result of such a bias.
We found that the Czechs (and to a lesser extent the Poles) drink often but relatively small amounts per occasion, while the Russians drink less often but large amounts per occasion. Previous studies in Russia also found infrequent drinking but high intake per occasion in men and relatively low consumption in women. ${ }^{22-25}$ Our ecological and individual level analyses show that the mean dose per session accounted for a substantial part of the differences in alcohol related problem in men in the three countries. These findings support the hypothesis that drinking pattern may potentiate the negative role of alcohol in Russia. ${ }^{26}$

Studies elsewhere point to drinking pattern as a potentially important contributor to differences in alcohol related problems between populations. For example, it has been proposed that binge drinking may explain the finding that the effect on homicide ${ }^{6}$ and suicide ${ }^{27}$ of changes in annual alcohol consumption is stronger in the Nordic countries than in southern Europe. Comparing Finland and Denmark in the 1960s, as the extremes within the Nordic countries, Finland had a lower per capita alcohol consumption, a lower cirrhosis mortality rate and more abstainers ${ }^{28}$ but higher rates of deaths from alcohol overdoses ${ }^{29}$ and of social disruption related to drinking, ranging from public nuisance to homicide. In the southern region of the United States, there was much more abstention from drinking, and the per capita alcohol consumption and the cirrhosis mortality rates were lower, while social disruption from drinking and homicide rates were higher. ${ }^{30}$

The distinctiveness of Russian male heavy drinking in this study is not in terms of larger amounts on once in a while occasions, but rather in larger amounts at the average session (although the drinking sessions happen less frequently than at least among Czech men). The somewhat complex findings suggest that patterns of heavy drinking in different populations need to be studied in considerable detail. One of the problems with using a summary term such as "binge drinking", as our data illustrate, is that it can hide great variation in how much is being drunk, and with what

Table 4 Odds ratios $(95 \% \mathrm{Cl})$ for problem drinking and negative consequences of drinking in men in Russia and Poland, compared with Czech Republic, in different statistical models

\begin{tabular}{|c|c|c|c|c|c|c|}
\hline \multirow[b]{2}{*}{ Variables in model } & \multicolumn{3}{|c|}{ Problem drinking ( $2+$ on CAGE) } & \multicolumn{3}{|c|}{ Negative consequences $(2+)$} \\
\hline & Czech & Russia & Poland & Czech & Russia & Poland \\
\hline \multicolumn{7}{|l|}{ Crude model } \\
\hline None & 1.0 & $2.4(1.7$ to 3.3$)$ & $0.7(0.4$ to 1.1$)$ & 1.0 & $1.9(1.2$ to 2.9$)$ & 0.810 .4 to 1.4 \\
\hline Mean dose & 1.0 & $1.6(1.1$ to 2.3$)$ & 0.7 (0.5 to 1.2$)$ & 1.0 & $1.5(1.0$ to 2.4$)$ & 0.9 (0.5 to 1.7 \\
\hline \multicolumn{7}{|l|}{ Adjusted for annual intake } \\
\hline Annual intake & 1.0 & $3.6(2.5$ to 5.3$)$ & $1.0(0.6$ to 1.7$)$ & 1.0 & $2.4(1.5$ to 3.8$)$ & 1.010 .6 to 1.8 \\
\hline Annual intake and mean dose & 1.0 & $2.4(1.6$ to 3.7$)$ & $1.1(0.6$ to 1.8$)$ & 1.0 & $1.9(1.2$ to 3.2$)$ & $1.1(0.6$ to 2.0 \\
\hline $\begin{array}{l}\text { Adjusted for annual intake and drinking frequency } \\
\text { Annual intake and drinking frequency }\end{array}$ & 1.0 & $4.4(2.9$ to 6.5$)$ & 1.5 (0.9 to 2.4$)$ & 1.0 & $2.9(1.8$ to 4.6$)$ & $1.4(0.8$ to 2.6 \\
\hline Annual intake, drinking frequency and mean dose & 1.0 & $2.7(1.8$ to 4.1$)$ & $1.5(0.9$ to 2.5$)$ & 1.0 & $2.2(1.3$ to 3.6$)$ & 1.510 .8 to 2.7 \\
\hline
\end{tabular}




\section{Policy implications}

- Controlling drinking volume alone will not be sufficient to control alcohol related problems. Drinking patterns need to be included in alcohol control policies.

- National guidelines on drinking should indicate both the overall volume (for example, less than 21 drinks per week) but also the dose (for example, less than 3-4 drinks per occasion) that is considered safe.

patterning. ${ }^{31}$ It is also possible that different beverages lead to different degree of problem drinking, depending on culture; the type of beverage may thus have contributed to the differences between the three populations.

The results of this study support the assignment of a high "hazardous drinking score" to Russia. ${ }^{89}$ However, the results do not support the assignment of a higher hazardous drinking score to Poland than to the Czech Republic, particularly when women's drinking is taken into account as well as men's. This discrepancy between the prediction and our finding may arise if Krakow is not entirely typical for Poland, but it may also indicate that expert judgements on drinking cultures typically pay more attention to men's than women's drinking. These results are a warning that this may be misleading, and that the overall volume of drinking is not sufficient to estimate the negative effects of alcohol at the population level.

\section{ACKNOWLEDGEMENTS}

M Bobak and M Marmot were members of the John D and Catherine $\mathrm{T}$ MacArthur Foundation Initiative on Health and Social Upheaval.

\section{Contributors}

M Bobak, M Marmot, A Pajak, R Kubinova, and S Malyutina developed the principal idea of the study, and S Kurilovitch, $\mathrm{H}$ Pikhart, R Topor, and Y Nikitin contributed to the study design. $\mathrm{R}$ Room advised on measurement of drinking pattern and alcohol related problems. M Bobak and H Pikhart analysed the data, and M Bobak and R Room drafted the paper. All co-authors participated in subsequent rewriting of the paper. M Bobak is the guarantor.

\section{Authors' affiliations}

M Bobak, H Pikhart, M Marmot, International Centre for Health and Society, Department of Epidemiology and Public Health, University College London, London, UK

R Room, Centre for Social Research on Alcohol and Drugs, Stockholm University, Sweden

R Kubinova, Centre for Environmental Health, National Institute of Public Health, Prague, Czech Republic

S Malyutina, Y Nikitin, Institute of Internal Medicine, Siberian Branch of Russian Academy of Medical Sciences, Novosibirsk, Russia

A Pajak, R Topor, Department of Epidemiology and Population

Sciences, Jagiellonian University, Krakow, Poland

Funding: the study was funded by the Wellcome Trust.

Conflicts of interest: none declared.

\section{REFERENCES}

1 Edwards G, Anderson P, Babor TF, et al. Alcohol policy and the public good. Oxford: Oxford University Press, 1994.
2 Knupfer G. Some methodological problems in the epidemiology of alcoholic beverage usage: definition of amount of intake. Am J Public Health Nations Health 1966;56:237-42.

3 Room R, Bondy SJ, Ferris J. The risk of harm to oneself from drinking, Canada 1989. Addiction 1995;90:499-513.

4 Murray RP, Connett JE, Tyas SL, et al. Alcohol volume, drinking pattern, and cardiovascular disease morbidity and mortality: is there a U-shaped function? Am J Epidemiol 2002;155:242-8.

5 Rehm J, Greenfield TK, Rogers JD. Average volume of alcohol consumption, patterns of drinking, and all-cause mortality: results from the US National Alcohol Study. Am J Epidemiol 2001;153:64-71.

6 Rossow I. Alcohol and homicide: a cross-cultural comparison of the relationship in 14 European countries. Addiction $2001 ; 96$ (suppl):S77-92.

7 Norstrom T, ed. Alcohol in postwar Europe: consumption, drinking patters, consequences and policy responses in 15 European countries. Stockholm: National Institute of Public Health, 2002.

8 Gmel G, Rehm J, Frick U. Methodological approaches to conducting pooled cross-sectional time series analysis: the example of the association between all-cause mortality and per capita alcohol consumption for men in 15 European states. Eur Addict Res 2001;7:128-37.

9 Rehm J, Monteiro M, Room R, et al. Steps towards constructing a global comparative risk analysis for alcohol consumption: determining indicators and empirical weights for patterns of drinking, deciding about theoretical minimum, and dealing with different consequences. Eur Addict Res 2001;7:138-47.

10 Rehm J, Room R, Monteiro M, et al. Comparative quantification of health risks: global and regional burden of disease due to selected major risk factors. Geneva: World Health Organisation, 2003.

11 Nemtsov A. Estimates of total alcohol consumption in Russia, 1980-1994. Drug Alcohol Depend 2000;58:133-43.

12 World Health Organisation. Global status report on alcohol. WHO/HSC/ SAB/99. 11 ed. Geneva: World Health Organisation, 1999.

13 Greenfield TK. Ways of measuring drinking patterns and the difference they make: experience with graduated frequencies. I Subst Abuse 2000;12:33-49.

14 Malyutina S, Bobak M, Kurilovitch S, et al. Relation between heavy and binge drinking and all-cause and cardiovascular mortality in Novosibirsk, Russia: a prospective cohort study. Lancet 2002;360:1448-54.

15 Ewing JA. Detecting alcoholism. The CAGE questionnaire. JAMA 1984;252:1905-7.

16 Rehm J, Frick U, Bondy S. A reliability and validity analysis of an alcoholrelated harm scale for surveys. J Stud Alcohol 1999;60:203-8.

17 Ramstedt M. Alcohol consumption and the experience of adverse consequences: a comparison of six European countries. Contemporary Drug Problems 2002;29:549-75.

18 Rehm J, Greenfield TK, Walsh G, et al. Assessment methods for alcohol consumption, prevalence of high risk drinking and harm: a sensitivity analysis. Int J Epidemiol 1999;28:219-24.

19 Midanik LT. Validity of self-reported alcohol use: a literature review and assessment. Br J Addiction 1988;83:1019-29.

20 Nemtsov A. Alcohol consumption in Russia: a viewpoint on monitoring health conditions in Russia (RLMS). Addiction 2003;98:369-70.

21 Simpura J, Levin BM, eds. Demystifying Russian drinking. Comparative studies from the 1990s. Helsinki: STAKES, 1997.

22 Bobak M, McKee $M$, Rose $R$, et al. Acohol consumption in a national sample of the Russian population. Addiction 1999;94:857-66.

23 Malyutina S, Bobak M, Kurilovitch S, et al. Alcohol consumption and binge drinking in Novosibirsk, Russia, 1985-95. Addiction 2001;96:987-95.

24 Carlson P, Vagero D. The social pattern of heavy drinking in Russia during transition. Evidence from Taganrog 1993. Eur J Public Health 1998;8:280-5.

25 Laatikainen T, Vartiainen E, Puska P, et al. Self-reported alcohol use and drinking habits in the Republic of Carelia, Russia and in North Carelia, Finland. In: Simpura J, Levin BM, eds. Demystifying Russian drinking: comparative studies from the 1990s. Helsinki: National Research and Development Centre for Welfare and Health, 1997:205-21.

26 Britton A, McKee M. The relation between alcohol and cardiovascular disease in Eastern Europe: explaining the paradox. J Epidemiol Community Health 2000;54:328-32.

27 Ramstedt M. Alcohol and suicide in 14 European countries. Addiction $2001 ; 96$ (suppl):S59-75.

28 Boston University Law-Medicine Institute. Scandinavian experience in legislation and control. Boston: Boston University Law-Medicine Institute, 1965.

29 Poikolainen K. Drug poisoning mortality trends in the Scandinavian countries 1961-1973. Scand J Soc Med 1977;5:115-21.

30 Room R. Interrelations of alcohol policies, consumption, and problems in the US states. Drinking and Drug Practices Surveyor 1974;9:21-31.

31 Wechsler H, Austin SB. Binge drinking: the five/four measure. J Stud Alcohol 1998; 59:122-4. 